\title{
Endothelial Dysfunction in a Rat Model of Endotoxic Shock Importance of the Activation of Poly (ADP-ribose) Synthetase by Peroxynitrite
}

Csaba Szabó, Salvatore Cuzzocrea, Basilia Zingarelli, Michael O’Connor, and Andrew L. Salzman
Children's Hospital Medical Center, Division of Critical Care, 3333 Burnet Avenue, Cincinnati, Ohio 45229

\begin{abstract}
DNA single strand breakage and activation of the nuclear enzyme poly (ADP-ribose) synthetase (PARS) contribute to peroxynitrite-induced cellular injury. We investigated the role of PARS activation in the pathogenesis of endothelial dysfunction. In human umbilical vein endothelial cells (HUVEC), DNA strand breakage (alkaline unwinding assay), PARS activation (incorporation or radiolabeled $\mathrm{NAD}^{+}$into proteins), mitochondrial respiration [conversion of 3-(4,5-dimethylthiazol-2-yl)-2,5-diphenyltetrazolium bromide to formazan] and apoptotic index (cytoplasmatic release of histones) were measured. Endotoxin shock was induced in rats by bacterial lipopolysaccharide. Vascular reactivity of thoracic aortic rings were measured in organ chambers. In HUVEC, peroxynitrite caused a dose-dependent suppression of mitochondrial respiration, induced DNA strand breakage and caused an activation of PARS. Pharmacological inhibition of PARS reduced the acute and delayed suppression of mitochondrial respiration when cells were exposed to intermediate, but not high doses of peroxynitrite. Similarly, protection against the intermediate, but not high doses of peroxynitrite was seen in fibroblasts from the PARS $^{-1-}$ mice, when compared to wild-type controls. These data suggest that PARS plays a role in peroxynitrite-induced cytotoxicity, but at very high levels of oxidant exposure, PARS-independent cytotoxic mechanisms become predominant. Peroxynitriteinduced apoptosis was not affected by PARS inhibition. Vascular rings exposed to peroxynitrite and rings taken from rats subjected to endotoxic shock exhibited reduced endothelium-dependent relaxant responses in response to acetylcholine. The development of this endothelial dysfunction was ameliorated by the PARS inhibitor 3-aminobenzamide. Activation of PARS by peroxynitrite, therefore, may be involved in the development of endothelial dysfunction in endotoxemia. (J. Clin. Invest. 1997. 100:723-735.) Key words: nitric oxide endothelium-derived factors $\bullet$ free radicals $\bullet$ antioxidants $\bullet$ shock
\end{abstract}

Address correspondence to Csaba Szabó, Children's Hospital Medical Center, Division of Critical Care, 3333 Burnet Avenue, Cincinnati, Ohio 45229. Phone: 513-636-8714; FAX: 513-636-4892; E-mail: csaba.szabo@chmcc.org

Received for publication 30 January 1997 and accepted in revised form 23 April 1997.

J. Clin. Invest.

(C) The American Society for Clinical Investigation, Inc. 0021-9738/97/08/0723/13 \$2.00

Volume 100, Number 3, August 1997, 723-735

http://www.jci.org

\section{Introduction}

Over the last several decades, there has been a substantial body of work implicating the pathophysiological roles of oxygen-derived free radicals in various forms of circulatory shock $(1,2)$. More recently, it also became evident that the free radical nitric oxide $(\mathrm{NO})^{1}$ serves a number of physiological and pathophysiological functions in the body, wherein the expression of the inducible isoform of NO synthase (NOS) has been proposed as an important mediator of the cardiovascular failure in shock $(3,4)$.

There is now substantial evidence that much of the oxidative injury associated with simultaneous production of $\mathrm{NO}$ and oxyradicals is mediated by peroxynitrite, a toxic oxidant formed from the reaction of $\mathrm{NO}$ and superoxide $(5,6)$. The formation of peroxynitrite has been demonstrated in various forms of shock, and some of the pathophysiological alterations attributed previously to NO or superoxide are now believed to be consequences of the actions of peroxynitrite $(5,6)$.

While peroxynitrite is capable of inactivating a variety of enzymes, thereby causing cellular injury, we have suggested recently a more complex mechanism that contributes to peroxynitrite toxicity in macrophages and smooth muscle cells (7-11). This pathway involves DNA single strand breakage in response to peroxynitrite, and consequent activation of the nuclear enzyme poly (ADP-ribose) synthetase (PARS). Massive ADP-ribosylation of nuclear proteins by PARS then results in energy depletion and cellular injury (7-11).

There is a substantial body of previous work implicating the role of oxyradicals in the pathogenesis of endothelial injury in ischemia reperfusion, shock, and atherosclerosis (12-16). More recently, it has been suggested that NO, derived from the endothelium, or from other sources, may combine with superoxide to form peroxynitrite, which, in turn, exerts cytotoxic effects to the endothelial cells $(6,12-15)$. Moreover, under conditions of intracellular L-arginine depletion, NOS itself may produce cytotoxic amounts of peroxynitrite (16).

Although there is a substantial body of evidence demonstrating the development of endothelial dysfunction in various pathophysiological states, and a link between free radicals, oxidants, and endothelial injury has been established, the cellular mechanisms leading to endothelial dysfunction are poorly defined. In this study we investigated whether (a) PARS activation is involved in the peroxynitrite-induced acute and delayed cytotoxicity in endothelial cells; $(b)$ whether peroxynitriteinduced endothelial dysfunction involves PARS activation in vascular rings in vitro; and $(c)$ whether the endothelial dys-

1. Abbreviations used in this paper: HUVEC, human umbilical vein endothelial cells; iNOS, inducible nitric oxide synthase; i.v., intravenous; MTT, 3-(4,5-dimethylthiazol-2-yl)-2,5-diphenyltetrazolium bromide; NO, nitric oxide; NOS, nitric oxide synthase; OD, optical density; PARS, poly (ADP-ribose) synthetase; SIN-1, 3-morpholino-sidnonimine; SNAP, S-nitroso- $N$-acetyl-DL-penicillamine. 
function associated with endotoxic shock involves PARS activation. Based on the current data, we propose a role for PARS activation in the endothelial injury associated with peroxynitrite and endotoxic shock. PARS inhibition may be a novel therapeutic opportunity to preserve endothelial function.

\section{Methods}

Cell culture. Human umbilical vein endothelial cells (HUVEC; American Type Culture Collection, Rockville, MD) were cultured in F12K medium, 10\% FBS, $100 \mu \mathrm{g} / \mathrm{ml}$ heparin, and $30 \mu \mathrm{g} / \mathrm{ml}$ endothelial cell growth supplement as described previously (17). Mouse embyo fibroblasts from the PARS ${ }^{-1-}$ mouse and fibroblasts from the corresponding wild-type controls (18) were grown in DME with $10 \%$ FBS.

Cells were cultured in 96 -well plates ( $200 \mu \mathrm{l}$ medium per well) or in 12 -well plates ( $3 \mathrm{ml}$ medium per well) until $90 \%$ confluence. Cells were exposed to peroxynitrite, hydrogen peroxide, or $\mathrm{NO}$ donor compounds in the presence or absence of a 10 min pretreatment with the PARS inhibitors. Typically, the PARS inhibitor 3-aminobenzamide was used at $1 \mathrm{mM}$. In a different set of studies, a range of PARS inhibitors nicotinamide (100 $\mu \mathrm{M}$ to $3 \mathrm{mM}), 3$-aminobenzamide $(100 \mu \mathrm{M}$ to $3 \mathrm{mM}$ ), and 5-iodo-6-amino-1,2-benzopyrone (10-100 $\mu \mathrm{M})$ and 3-aminobenzoic acid $(1 \mathrm{mM})$ (the inactive structural analog of 3-aminobenzamide) (19) were tested against the cytotoxic effect of $500 \mu \mathrm{M}$ peroxynitrite.

Typically, cells were exposed to peroxynitrite in the same medium that was used for growing the cells. In a separate set of experiments, in order to study the role of extracellular and intracellular scavengers on the peroxynitrite-induced cytotoxicity, medium was replaced with PBS ( $\mathrm{pH}$ 7.4) and cells then exposed to peroxynitrite $(1 \mu \mathrm{M}$ to $1 \mathrm{mM})$ for $1 \mathrm{~h}$. For the depletion of endogenous glutathione in the cells, a 24-h pretreatment with L-buthionine-(S,R)-sulfoximide (BSO), an inhibitor of gamma-glutamylcysteine synthetase was used as described (20). To study the potential effect of extracellular glutathione, cells were pretreated with $3 \mathrm{mM}$ glutathione $10 \mathrm{~min}$ before peroxynitrite exposure.

Measurement of mitochondrial respiration. At $60 \mathrm{~min}$ or $24 \mathrm{~h}$ after peroxynitrite exposure, cell respiration was assessed by the mitochondrial-dependent reduction of 3-(4,5-dimethylthiazol-2-yl)-2,5-diphenyltetrazolium bromide (MTT) to formazan (7-9). Cells in 96-well plates were incubated at $37^{\circ} \mathrm{C}$ with MTT $(0.2 \mathrm{mg} / \mathrm{ml})$ for $1 \mathrm{~h}$. Culture medium was removed by aspiration and the cells were solubilized in DMSO $(100 \mu \mathrm{l})$. The extent of reduction of MTT to formazan within cells was quantitated by the measurement of $\mathrm{OD}_{550}$. As discussed previously (9), this method appears to be mainly by the mitochondrial complexes I and II; it also may involve NADH- and NADPH-dependent energetic processes that occur outside the mitochondrial inner membrane. Thus, the method cannot be used to separate the effect of free radicals, oxidants, or other factors on the individual enzymes in the mitochondrial respiratory chain, but is useful to monitor changes in the general energetic status (9).

Determination of DNA single strand breaks. At $10 \mathrm{~min}$ after peroxynitrite exposure, the formation of strand breaks in doublestranded DNA was determined by the alkaline unwinding method as described previously (7-9). Cells in 12-well plates were scraped into $0.2 \mathrm{ml}$ of solution A-buffer (myoinositol $250 \mathrm{mM}, \mathrm{NaH}_{2} \mathrm{PO}_{3} 10 \mathrm{mM}$, $\mathrm{MgCl}_{2} 1 \mathrm{mM}, \mathrm{pH}$ 7.2). The cell lysate was then transferred into plastic tubes designated $\mathrm{T}$ (maximum fluorescence), $\mathrm{P}$ (fluorescence in sample used to estimate extent of DNA unwinding), or B (background fluorescence). To each tube, $0.2 \mathrm{ml}$ of solution B (alkaline lysis solution: $\mathrm{NaOH} 10 \mathrm{mM}$, urea $9 \mathrm{M}$, ethylenediaminetetraacetic acid 2.5 $\mathrm{mM}$, sodium dodecyl sulfate $0.1 \%$ ) was added and incubated at $4^{\circ} \mathrm{C}$ for $10 \mathrm{~min}$ to allow cell lysis and chromatin disruption. $0.1 \mathrm{ml}$ each of solutions $\mathrm{C}(0.45 \mathrm{vol}$ solution $\mathrm{B}$ in $0.2 \mathrm{~N} \mathrm{NaOH})$ and $\mathrm{D}(0.4 \mathrm{vol}$ solution $\mathrm{B}$ in $0.2 \mathrm{~N} \mathrm{NaOH}$ ) was then added to the $\mathrm{P}$ and $\mathrm{B}$ tubes. $0.1 \mathrm{ml}$ of solution $\mathrm{E}$ (neutralizing solution: glucose $1 \mathrm{M}$, mercaptoethanol $14 \mathrm{mM}$ ) was added to the $\mathrm{T}$ tubes before solutions $\mathrm{C}$ and $\mathrm{D}$ were added. From this point incubations were carried out in the dark. A 30-min incubation period at $0^{\circ} \mathrm{C}$ was then allowed during which the alkali diffused into the viscous lysate. Since the neutralizing solution, solution E, was added to the $\mathrm{T}$ tubes before addition of the alkaline solutions $\mathrm{C}$ and $\mathrm{D}$, the DNA in the T tubes was never exposed to a denaturing $\mathrm{pH}$. At the end of the $30 \mathrm{~min}$ incubation, the contents of the $\mathrm{B}$ tubes were sonicated for $30 \mathrm{~s}$ to ensure rapid denaturation of DNA in the alkaline solution. All tubes were then incubated at $15^{\circ} \mathrm{C}$ for $10 \mathrm{~min}$. Denaturation was stopped by chilling to $0^{\circ} \mathrm{C}$ and adding $0.4 \mathrm{ml}$ of solution $\mathrm{E}$ to the $\mathrm{P}$ and $\mathrm{B}$ tubes. $1.5 \mathrm{ml}$ of solution $\mathrm{F}$ (ethidium bromide $6.7 \mu \mathrm{g}$ / $\mathrm{ml}$ in $13.3 \mathrm{mM} \mathrm{NaOH}$ ) was added to all the tubes and fluorescence (excitation: $520 \mathrm{~nm}$; emission: $590 \mathrm{~nm}$ ) was measured by a PerkinElmer fluorimeter. Under the conditions used, in which ethidium bromide binds preferentially to double stranded DNA, the percentage of double stranded DNA (D) may be determined using the equation: \% $\mathrm{D}=100 \mathrm{X}[\mathrm{F}(\mathrm{P})-\mathrm{F}(\mathrm{B})] /[\mathrm{F}(\mathrm{T})-\mathrm{F}(\mathrm{B})]$; where $\mathrm{F}(\mathrm{P})$ is the fluorescence of the sample, $\mathrm{F}(\mathrm{B})$ the background fluorescence, i.e. fluorescence due to all cell components other than double stranded DNA, and $\mathrm{F}(\mathrm{T})$ the maximum fluorescence.

Measurement of cellular PARS activity. $10 \mathrm{~min}$ after peroxynitrite exposure, the culture medium in 12-well plates was replaced with $0.5 \mathrm{ml}$ of $56 \mathrm{mM}$ Hepes buffer, $\mathrm{pH} 7.5$, containing $28 \mathrm{mM} \mathrm{KCl}, 28 \mathrm{mM}$ $\mathrm{NaCl}, 2 \mathrm{mM} \mathrm{MgCl}, 0.01 \%$ digitonin, and $125 \mathrm{nmol} \mathrm{NAD}^{+}$spiked with $0.25 \mu \mathrm{Ci}\left[{ }^{3} \mathrm{H}\right] \mathrm{NAD}^{+}$. PARS activity was then measured as described (7-9). Digitonin was used to permeabilize plasma membranes (7-9). The permeabilized cells were incubated for $5 \mathrm{~min}$ at $37^{\circ} \mathrm{C}$, and the protein that was ribosylated with $\left[{ }^{3} \mathrm{H}\right] \mathrm{NAD}^{+}$was precipitated with $200 \mu \mathrm{l}$ of $50 \%$ TCA. After two washes with TCA, the protein pellet was solubilized in $2 \%$ SDS in $0.1 \mathrm{M} \mathrm{NaOH}$, incubated at $37^{\circ} \mathrm{C}$ overnight, and the radioactivity was determined by a Wallac $1450 \mathrm{Mi}-$ crobeta Plus scintillation counter (Wallac, Gaithersburg, MD).

Measurement of ADP-ribosylation in soluble extracts of HUVEC. Cells were treated with peroxynitrite or hydrogen peroxide in the absence or presence of PARS inhibitors and incubated for $10 \mathrm{~min}$ in Hepes buffer containing $125 \mathrm{nM}$ NAD and $2 \mu \mathrm{Ci}$ of [ $\left.{ }^{32} \mathrm{P}\right] \mathrm{NAD}(37$ $\mathrm{kBq}$ ). ADP-ribosylation in soluble extracts of HUVEC was then measured as described (7). Proteins were precipitated with $200 \mu \mathrm{l}$ $50 \%$ trichloroacetic acid. The precipitates were centrifuged at $10,000 \mathrm{~g}$ for $10 \mathrm{~min}$ and pellets were washed once with $0.5 \mathrm{ml} 5 \%$ trichloroacetic acid and once with $0.5 \mathrm{ml}$ water saturated diethylether solution and resuspended in $200 \mu \mathrm{l}$ of $62.5 \mathrm{mM}$ Tris- $\mathrm{HCl}, \mathrm{pH} 6.8$, buffer containing $10 \%$ glycerol, $2 \%$ SDS, $5 \%$ 2-mercaptoethanol, and $0.00125 \%$ Bromophenol Blue. The resulting preparations were heated at $100^{\circ} \mathrm{C}$ for $5 \mathrm{~min}$ and loaded onto a $7.5 \%$ polyacrylamide gel containing $0.1 \%$ SDS. Gels were run at $35 \mathrm{~mA}$ for $4.5 \mathrm{~h}$ in Laemmli buffer $(0.3 \%$ Trizma, $\mathrm{pH} 8.3$, containing $1.44 \%$ glycine and $0.1 \%$ SDS). Gels were dried and exposed to Fuji RX film for $24 \mathrm{~h}$ with intensifying screens. Radiolabeled polypeptides were visualized by autoradiography.

Measurement of the cytoplasmatic accumulation of histones as an indicator of apoptotic DNA fragmentation. At $24 \mathrm{~h}$ after peroxynitrite exposure, cells were assayed for the quantitation of free histones in the cytoplasm according to principles described previously (21). Briefly, supernatants were removed by aspiration, $100 \mu \mathrm{l}$ of lysis buffer was added to each well and the plates were incubated for 10 $\min$ at $4^{\circ} \mathrm{C}$. The cells were then scraped and transferred to microfuge tubes containing $400 \mu \mathrm{l}$ of lysis buffer. Tubes were incubated an additional $20 \mathrm{~min}$ at $4^{\circ} \mathrm{C}$ then centrifuged at $14,000 \mathrm{~g}$ for $10 \mathrm{~min}$ at $4^{\circ} \mathrm{C}$. $50 \mu \mathrm{l}$ of this lysate was further diluted 1:5 in lysis buffer and $100 \mu \mathrm{l}$ in duplicate added to the ELISA plate coated with antihistone antibody according to the manufacturer's instructions. The samples were removed after 90 min incubation at room temperature and after the plate was washed according to protocol. $100 \mu$ l of anti-DNA-peroxidase was added to each well and allowed to react at room temperature for $90 \mathrm{~min}$. The plate was again washed according to protocol and $100 \mu \mathrm{l}$ of color development solution containing 2,2'-azino-di-3ethylbenzthiazoline sulfonate (ABTS) was added to each well and 
the plate shaken on an orbital shaker, $500 \mathrm{rpm}$ for 10 minutes. Absorbance was then measured (405-490 nm) versus substrate solution as a blank. Apoptotic index was calculated by dividing the absorbance in the treatment groups with the absorbance of the untreated control cells.

Measurement of isometric force in vascular rings. Thoracic aortae from rats were cleared of adhering periadventitial fat and cut into rings of 3-4 mm width. Rings in Kreb's solution were exposed to $\mathrm{ONOO}^{-}(600 \mu \mathrm{M})$ or vehicle control, in the presence of absence of $1 \mathrm{mM}$ 3-aminobenzamide. After a $30 \mathrm{~min}$ incubation, rings were mounted in organ baths $(5 \mathrm{ml})$ filled with warmed $\left(37^{\circ} \mathrm{C}\right)$, oxygenated (95\% O2/5\% $\mathrm{CO}_{2}$ ) Krebs' solution ( $\mathrm{pH} 7.4$ ) consisting of (in $\mathrm{mM}$ ): $\mathrm{NaCl} 118, \mathrm{KCl} 4.7, \mathrm{KH}_{2} \mathrm{PO}_{4} 1.2, \mathrm{MgSO}_{4} 1.2, \mathrm{CaCl}_{2} 2.5, \mathrm{NaHCO}_{3} 25$, and glucose 11.7. Experiments were performed in the presence of indomethacin $(10 \mu \mathrm{M})$, to prevent the generation of cyclooxygenase metabolites. Isometric force was measured with isometric transducers (Kent Scientific Corp., Litchfield, CT), digitized using a Maclab A/D converter (AD Instruments, Milford, MA), and stored and displayed on a Macintosh personal computer (9). A tension of $1 \mathrm{~g}$ was applied and the rings were equilibrated for $60 \mathrm{~min}$. Fresh Krebs' solution was provided at $15 \mathrm{~min}$ intervals. Rings were then precontracted with noradrenaline $\left(10^{-6} \mathrm{M}\right)$, and then concentration-response curves to acetylcholine $\left(10^{-9}-10^{-5} \mathrm{M}\right)$ and to the NO donor S-nitroso- $N$-acetyl-DLpenicillamine (SNAP) $\left(10^{-7}-10^{-5} \mathrm{M}\right)$ were obtained.

Endotoxic shock induced endothelial dysfunction. Male Wistar rats (Charles River Laboratories, Wilmington, MA) were injected with Escherichia coli LPS (15 mg/kg i.v.) at time 0 . Rats were injected with intravenous saline $(0.2 \mathrm{ml} / \mathrm{kg})$ or 3 -aminobenzamide $(10 \mathrm{mg} / \mathrm{kg}$ i.v. in $0.2 \mathrm{ml} / \mathrm{kg}$ saline) at $1 \mathrm{~h}$ post-LPS and again at $3 \mathrm{~h}$ post-LPS and killed at $6 \mathrm{~h}$ after LPS injection. This protocol was chosen in order to avoid potential interference of the PARS inhibitor with the process of inducible NOS (iNOS) induction that starts 60-90 min after LPS injection and peaks $6 \mathrm{~h}$ after LPS in this experimental model (22). In the control groups of rats, animals were injected with vehicle (saline, $0.1 \mathrm{ml} / \mathrm{kg}$ i.v.) at time $0 \mathrm{~min}$. At 1 and $3 \mathrm{~h}$, rats were injected with 3 -aminobenzamide $(10 \mathrm{mg} / \mathrm{kg}$ i.v. in $0.1 \mathrm{ml} / \mathrm{kg}$ saline $)$ and killed at $6 \mathrm{~h}$.

Thoracic aortic rings were taken from the various groups of animals and processed for the measurement of endothelium-dependent and endothelium-independent relaxations as described above.

NOS assay. Calcium-independent conversion of L-arginine to L-citrulline in homogenates of lungs served as an indicator of tissue iNOS activity (22). Lungs were taken from the animals and stored at $-70^{\circ} \mathrm{C}$. Lungs were homogenized on ice in a buffer composed of $50 \mathrm{mM}$ Tris- $\mathrm{HCl}, 0.1 \mathrm{mM}$ EDTA, and $1 \mathrm{mM}$ phenylmethylsulphonyl fluoride ( $\mathrm{pH}$ 7.4) on ice using a Tissue Tearor 985-370 homogenizer (Biospec
Products, Inc., Bartlesville, OK). Conversion of $\left[{ }^{3} \mathrm{H}\right] \mathrm{L}-$ arginine to $\left[{ }^{3} \mathrm{H}\right] \mathrm{L}$-citrulline was measured in the homogenates as described (13). Briefly, homogenates $(30 \mu \mathrm{l})$ were incubated in the presence of $\left[{ }^{3} \mathrm{H}\right] \mathrm{L}$-arginine $(10 \mu \mathrm{M}, 5 \mathrm{kBq}$ per tube), NADPH $(1 \mathrm{mM})$, calmodulin $(30 \mathrm{nM})$, tetrahydrobiopterin $(5 \mu \mathrm{M})$, and EGTA $(2 \mathrm{mM})$ for 20 $\mathrm{min}$ at $22^{\circ} \mathrm{C}$. Reactions were stopped by dilution with $0.5 \mathrm{ml}$ of icecold Hepes buffer ( $\mathrm{pH} 5.5)$ containing EGTA ( $2 \mathrm{mM}$ ) and EDTA $(2 \mathrm{mM})$. Reaction mixtures were applied to Dowex 50W $\left(\mathrm{Na}^{+}\right.$form) columns and the eluted $\left[{ }^{3} \mathrm{H}\right] \mathrm{L}$-citrulline activity was measured by a Wallac scintillation counter (Wallac).

iNOS activity was compared in lung samples obtained from the following groups: control; control +3 -aminobenzamide; LPS; and LPS + 3-aminobenzamide.

Plasma nitrite plus nitrate production. In plasma samples, nitrate is the major degradation product of NO. Nitrate was converted to nitrite by incubation with $60 \mathrm{mU}$ nitrate reductase and $25 \mu \mathrm{M}$ NADPH for $180 \mathrm{~min}$. Nitrite was then measured as described previously (8) by adding Griess reagent ( $1 \%$ sulphanilamide and $0.1 \%$ naphthylethylenediamine in 5\% phosphoric acid) to plasma samples diluted (1:10) in PBS. The optical density at $550 \mathrm{~nm}\left(\mathrm{OD}_{550}\right)$ was measured. Nitrite plus nitrate concentrations were calculated by comparison with $\mathrm{OD}_{550}$ of standard solutions of sodium nitrite and sodium nitrate. The measurements of nitrite plus nitrate were performed using reagents free of nitrite and nitrate: no basal or background nitrite or nitrate levels were detected.

Plasma nitrite plus nitrate concentrations were compared in lung samples obtained from the following groups: control; control +3 -aminobenzamide; LPS and LPS + 3-aminobenzamide.

Materials. Cell culture medium, heparin and FCS were obtained from GIBCO BRL (Gaithersburg, MD). Perchloric acid was obtained from Aldrich (St. Louis, MO). S-nitroso- $N$-acetyl-DL-penicillamine (SNAP) was purchased from Calbiochem Corp. (San Diego, CA). Diethylamine NONOate was purchased from Cayman Chemical Co., Inc. (Ann Arbor, MI) and 3-morpholino-sidnonimine (SIN-1) was obtained from Cassella AG (Frankfurt, Germany). $\left[{ }^{3} \mathrm{H}\right] \mathrm{NAD}^{+}$ was purchased from DuPont-NEN (Boston, MA). The apoptosis ELISA kit was obtained from Boehringer Mannheim Biochemicals (Indianapolis, IN). Bacterial LPS (E. coli, serotype No. 0127:B8), and all other chemicals were from Sigma Chemical Co. (St. Louis, MO). The fibroblast lines derived from the $\mathrm{PARS}^{-/-}$and $\mathrm{PARS}^{+/+}$mice (18) were kind gifts of Dr. Z.Q. Wang (Institute of Molecular Pathology, Vienna, Austria). The PARS inhibitor 5-iodo-6-amino-1,2-benzopyrone (23) was a kind gift of Prof. E. Kun (San Francisco State University, Tiburon, CA). Peroxynitrite was synthesized and kindly provided by Dr. H. Ischiropoulos (University of Pennsylvania, Philadelphia, PA).



Figure 1. Protective effects of PARS inhibition by 3 -aminobenzamide against the suppression of mitochondrial respiration triggered by authentic peroxynitrite $(250 \mu \mathrm{M}$ to $1 \mathrm{mM}$ ) in HUVEC. Closed bars represent the effect of peroxynitrite alone; hatched bars represent mitochondrial respiration in the presence of the PARS inhibitor 3-aminobenzamide $(1 \mathrm{mM}) . * * P<0.01$ represents significant suppression of the mitochondrial respiration elicited by peroxynitrite when compared to unstimulated controls; ${ }^{\#} P<0.01$ represents significant protection by 3 -aminobenzamide. Data are expressed as means \pm SEM of $n=6-12$ wells. 




Figure 2. PARS activation in response to authentic peroxynitrite $(250 \mu \mathrm{M}$ to $1 \mathrm{mM})$ in HUVEC. Closed bars represent the effect of peroxynitrite alone, hatched bars represent PARS activity in the presence of the PARS inhibitor 3-aminobenzamide $(1 \mathrm{mM}) . * * P<$ 0.01 represents significant suppression of the mitochondrial respiration elicited by peroxynitrite when compared to unstimulated controls; ${ }^{\#} P<0.01$ represents significant reduction of PARS activity by 3 -aminobenzamide. Data are expressed as means \pm SEM of $n=6-12$ wells.
Data analysis. All values in the figures and text are expressed as mean \pm SEM of $n$ observations, where $n$ represents the number of wells or vascular rings studied (6-9 wells or rings from 2-3 independent experiments). Data sets were examined by one- and two-way ANOVA and individual group means were then compared with a Student's unpaired $t$ test. A $P$-value $<0.05$ was considered significant.

\section{Results}

Role of PARS activation in the peroxynitrite-mediated inhibition of mitochondrial respiration in endothelial cells. Exposure of HUVEC to peroxynitrite $(250 \mu \mathrm{M}$ to $1 \mathrm{mM})$ caused a dosedependent suppression of the mitochondrial respiration at $1 \mathrm{~h}$ (Fig. 1). In addition, peroxynitrite caused a dose-dependent increase in the percentage of single-stranded DNA in these cells. For instance, at $250 \mu \mathrm{M}$, the percentage of single stranded DNA increased from $4 \pm 6 \%$ to $35 \pm 6 \%(P<0.01)$, and at 1 $\mathrm{mM}$ peroxynitrite, the percentage of single stranded DNA amounted to $56 \pm 3 \%(P<0.01)(n=6)$. Peroxynitrite also caused a dose-dependent activation of PARS (Fig. 2), with some basal PARS activity also detectable in control (unstimulated) HUVEC (Fig. 2). Autoradiography demonstrated a significant ADP-ribosylation in the extracts of HUVEC after peroxynitrite treatment, which was inhibited significantly by 3-aminobenzamide pretreatment (Fig. 3). Much of the ADPribosylation was detected for a protein of $\sim 130 \mathrm{kD}$, (Fig. 3) that is consistent with autoribosylation of PARS itself (7). With the exposure time used for the generation of the autoradiogram shown in Fig. 3, basal PARS activity was not detectable. However, (and in accordance with the data shown in Fig. 2), longer exposure times revealed a significant basal PARS activity in unstimulated control HUVEC (not shown).

Pretreatment of the cells with the PARS inhibitor 3-aminobenzamide at $1 \mathrm{mM}$ prevented PARS activation in response to peroxynitrite (Fig. 2), without affecting the extent of DNA single strand breakage. For instance, the percentage of single stranded DNA amounted to $58 \pm 4 \%$ in the presence of 3 -aminobenzamide, after exposure to $1 \mathrm{mM}$ peroxynitrite $(n=6)$. Pharmacological inhibition of PARS caused a significant protection against the peroxynitrite-induced suppression of mito- chondrial respiration at $500 \mu \mathrm{M}$ peroxynitrite (Fig. 1). At this dose, peroxynitrite caused an $\sim 50 \%$ inhibition of the mitochondrial respiration (Fig. 1). However, when HUVEC were exposed to higher concentrations of peroxynitrite, there was a more pronounced suppression of mitochondrial respiration, which was, however, no longer prevented by 3-aminobenzamide (Fig. 1), despite the fact that 3-aminobenzamide was still able to prevent PARS activation in response to these higher concentrations of peroxynitrite (Fig. 2).

Next, we investigated the effect of a range of PARS inhibitors against the peroxynitrite $(500 \mu \mathrm{M})$ induced cytotoxicity in HUVEC (Fig. $4 a$ ). There was a dose-dependent protection with 3 -aminobenzamide $(100 \mu \mathrm{M}$ to $3 \mathrm{mM})$, with the lowest effective dose being $1 \mathrm{mM}$. In contrast, 3-aminobenzoic acid, a structural analog of 3-aminobenzamide, which lacks inhibitory effect on PARS (19) did not protect HUVEC against peroxynitrite toxicity (Fig. $4 a$ ). While the protective effect of nicotinamide was apparent in the dose range similar to those of 3-aminobenzamide, the novel, more potent PARS inhibitor 5-iodo-6-amino-1,2-benzopyrone (23) already provided protection at a concentration of $100 \mu \mathrm{M}$ (Fig. $4 a$ ). Although these



Figure 3. Autoradiography of ADP-ribosylated polypeptides in HUVEC extracts in control conditions (first lane), in control conditions in the presence of 3-aminobenzamide (3-AB) (second lane), at $10 \mathrm{~min}$ after exposure to $1 \mathrm{mM}$ peroxynitrite $\left(\mathrm{ONOO}^{-}\right)$(third lane), and $10 \mathrm{~min}$ after $500 \mu \mathrm{M}$ peroxynitrite in the presence of $1 \mathrm{mM}$ 3-aminobenzamide (fourth lane). 
a

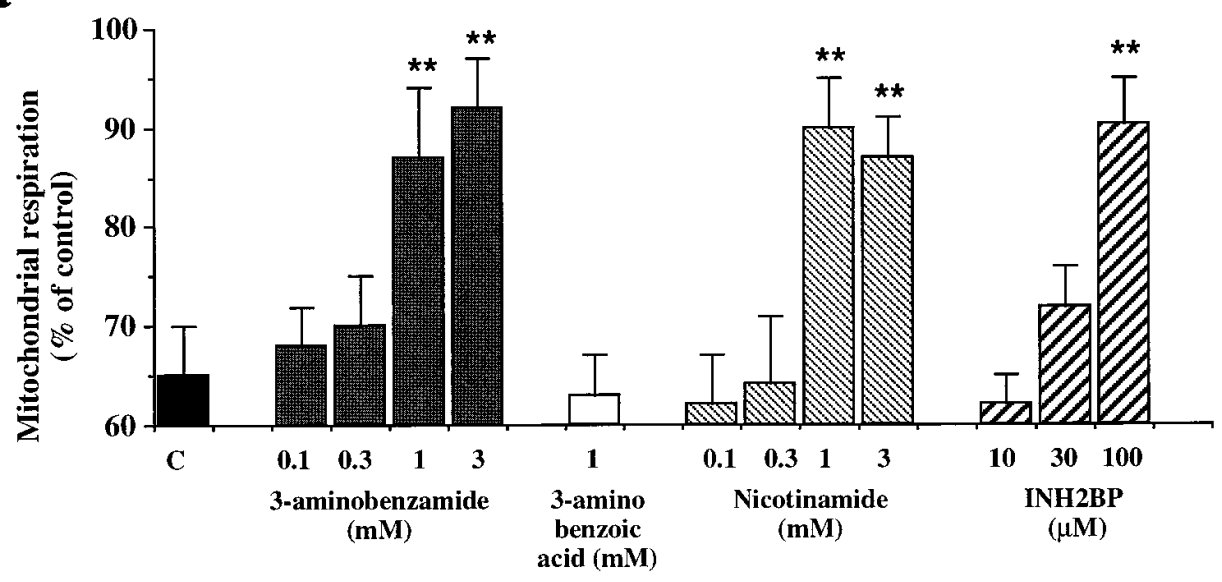

b

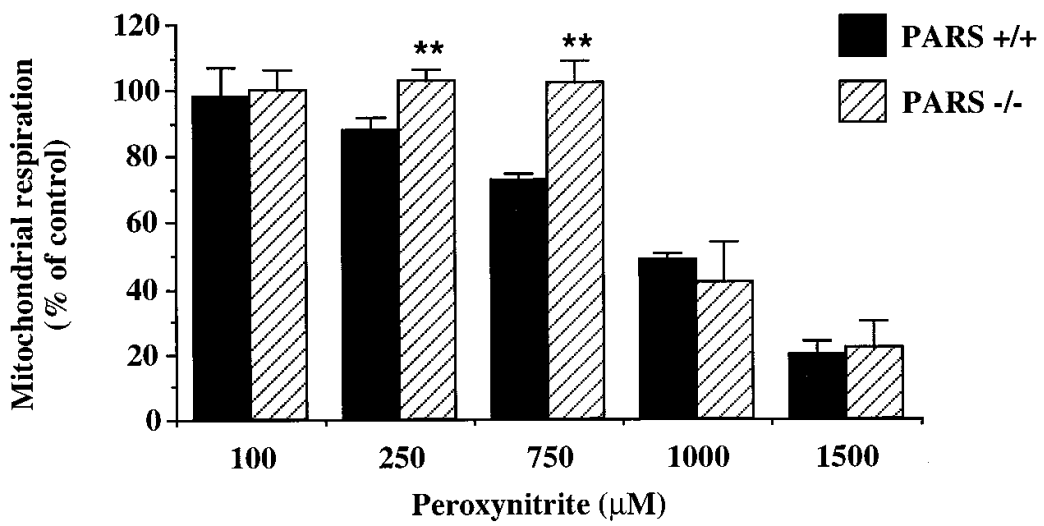

Figure 4. (a) Effect of various concentrations of 3-aminobenzamide, nicotinamide, 5-iodo-6-amino-1,2benzopyrone and 3-aminobenzoic acid on the suppression of mitochondrial respiration in response to $500 \mu \mathrm{M}$ peroxynitrite in HUVEC. (b) Comparison of the suppression of mitochondrial respiration in response to increasing concentrations of peroxynitrite in fibroblasts from PARS $^{-/}$and PARS ${ }^{+/+}$mice. Data are expressed as percentage of values in unstimulated controls. $* * P<$ 0.01 represent significant protection against the peroxynitrite-induced suppression of mitochondrial respiration by the PARS inhibitors or by the PARS $^{-1-}$ phenotype. Data are expressed as means \pm SEM of $n=6-12$ wells. pharmacological studies already strongly suggested that the protective effect seen with multiple inhibitors is, indeed, related to PARS activity, we repeated our studies in a fibroblast cell line derived from the PARS ${ }^{-1-}$ mice (18), and compared the effect to the response in the corresponding fibroblast line derived from the respective wild-type control (Fig. $4 b$ ). The fibroblast line was somewhat less sensitive to peroxynitrite injury than the HUVEC. However, similar to the effect of the pharmacological inhibitors, cells from the $\mathrm{PARS}^{-1-}$ mice were protected against intermediate $(250-750 \mu \mathrm{M})$, but not high (1-1.5 mM) concentrations. These results, again, suggest that at extremely high oxidant concentrations, overwhelming, PARS-independent mechanisms of cytotoxicity become activated. This finding is in accordance with recent observations in pancreatic islet cells and in macrophages, where extremely high concentrations of oxidants caused massive cytotoxicity, which was no longer preventable by blockade of PARS $(7,24)$.

To establish the relative inhibitory potency of 3-aminobenzamide on NO versus peroxynitrite-induced suppression of respiration, HUVEC were exposed to compounds spontaneously releasing NO (diethyltriamine NONOate and SNAP, $3 \mathrm{mM}$ each) or to 3-morpholino-sidnonimine (SIN-1, $3 \mathrm{mM}$ ), a compound that releases $\mathrm{NO}$ and superoxide anion in equimolar amounts (25). SIN-1 and hydrogen peroxide (but not SNAP) induced significant PARS activation (Fig. 5). Although all three compounds tested inhibited mitochondrial respiration, protection by 3-aminobenzamide was only observed against the SIN-1 and hydrogen-peroxide induced suppression of mitochondrial respiration (Fig. 5), and 3-aminobenzamide did not inhibit the suppression of mitochondrial respiration in response to the NO donors nitroso- $N$-acetyl-DL-penicillamine SNAP (Fig. 5) or diethyltriamine NONOate (not shown). These data support the view (see references 7-11) that peroxynitrite and NO elicit cytotoxicity via different molecular mechanisms, and the injury in response to pure NO does not involve PARS activation.

Cytotoxic and cytoprotective interactions of peroxynitrite with exogenous and endogenous scavengers and with hydroxyl radical and NO. The concentrations of peroxynitrite required to induce cytotoxicity were rather high in the current study (low millimolar range). Therefore, we sought to establish whether endogenous antioxidants play a protective role against peroxynitrite-induced cytotoxicity. We found that when HUVEC were challenged with peroxynitrite in PBS (rather than culture medium), there was a marked shift to the left in the dose-response curve, and peroxynitrite concentra- 



Figure 5. PARS activation $(a)$ and mitochondrial respiration $(b)$ in HUVEC in response to the peroxynitrite donor SIN-1 (SIN, $3 \mathrm{mM})$, the NO donor (SNAP, $3 \mathrm{mM}$ ) and by hydrogen peroxide ( $\mathrm{H} 2 \mathrm{O} 2$, $10 \mu \mathrm{M})$ : effect of 3-aminobenzamide $(1 \mathrm{mM})$ on these responses. Closed bars represent the effect of peroxynitrite alone, hatched bars represent values in the presence of the PARS inhibitor 3-aminobenzamide $(1 \mathrm{mM}) . * * P<0.01$ represents significant effect elicited by the various agents when compared to unstimulated controls; ${ }^{\# \#} P<0.01$ represents significant protection by 3 -aminobenzamide. Data are expressed as means \pm SEM of $n=6-12$ wells.

tions as low as $30 \mu \mathrm{M}$ caused a $50 \%$ suppression of mitochonrial respiration (Fig. $6 a$ ). These data suggest that medium and serum constituents play an important role in inactivating peroxynitrite extracellularly. More importantly, depletion of the HUVEC of their endogenous glutathione pools by the use of a 24-h pretreatment with BSO, caused a significant enhancement of the cytotoxicity, emphasizing the importance of intracellular glutathione as an antioxidant and a protecting factor against peroxynitrite toxicity (Fig. $6 a$ ). On the other hand, extracellular glutathione $(3 \mathrm{mM})$ protected against peroxynitriteinduced cytotoxity (Fig. $6 a$ ).

Since in circulatory shock and in other pathophysiological conditions, NO, peroxynitrite, and hydroxyl radical may be produced simultaneously, we also investigated the cytotoxic or cytoprotective interaction of peroxynitrite, $\mathrm{NO}$, and hydroxyl radical in HUVEC. As shown in Fig. $6 b$, there is a synergistic cytotoxic interaction between low concentrations of peroxynitrite and hydroxyl radical (generated from hydrogen peroxide). This synergy was also present at the level of PARS activation (not shown). On the other hand, a treatment with a noncytotoxic concentration of the NO donor compound SNAP (1 mM) reduced the degree of the peroxynitrite-induced suppression of mitochondrial respiration (Fig. $6 b$ ).
Role of PARS activation in the peroxynitrite-mediated apoptotic DNA fragmentation in endothelial cells. Peroxynitrite caused a delayed DNA fragmentation in HUVEC at $24 \mathrm{~h}$ (Fig. 7). The DNA fragmentation occurred at concentrations lower than the ones required for inhibition of mitochondrial respiration (i.e., already at $100 \mu \mathrm{M}$ peroxynitrite). The degree of apoptotic DNA fragmentation was unaffected by inhibition of PARS with 3-aminobenzamide (Fig. 7). At this time point ( $24 \mathrm{~h})$, similar to the results obtained at $1 \mathrm{~h}$ after peroxynitrite, 3 -aminobenzamide still protected against the suppression of the mitochondrial respiration elicited by lower concentrations $(250$ and $500 \mu \mathrm{M}$ ) of peroxynitrite, but not against the suppression elicited by higher concentrations $(750 \mu \mathrm{M}$ to $1 \mathrm{mM})$ of peroxynitrite or against the cytotoxicity elicited by the NO donor compound SNAP (Fig. 7).

$P A R S$ inhibition reduces the peroxynitrite induced endothelial dysfunction in vascular rings. Exposure of vascular rings with intact endothelium to peroxynitrite caused a marked impairment of the endothelium-dependent relaxations (Fig. 8). This effect appeared to be related to a reduced ability of the vascular endothelium to generate NO, and not due to a reduced ability of the vascular smooth muscle to relax in response to NO, since the relaxant effect of the NO donor com- 


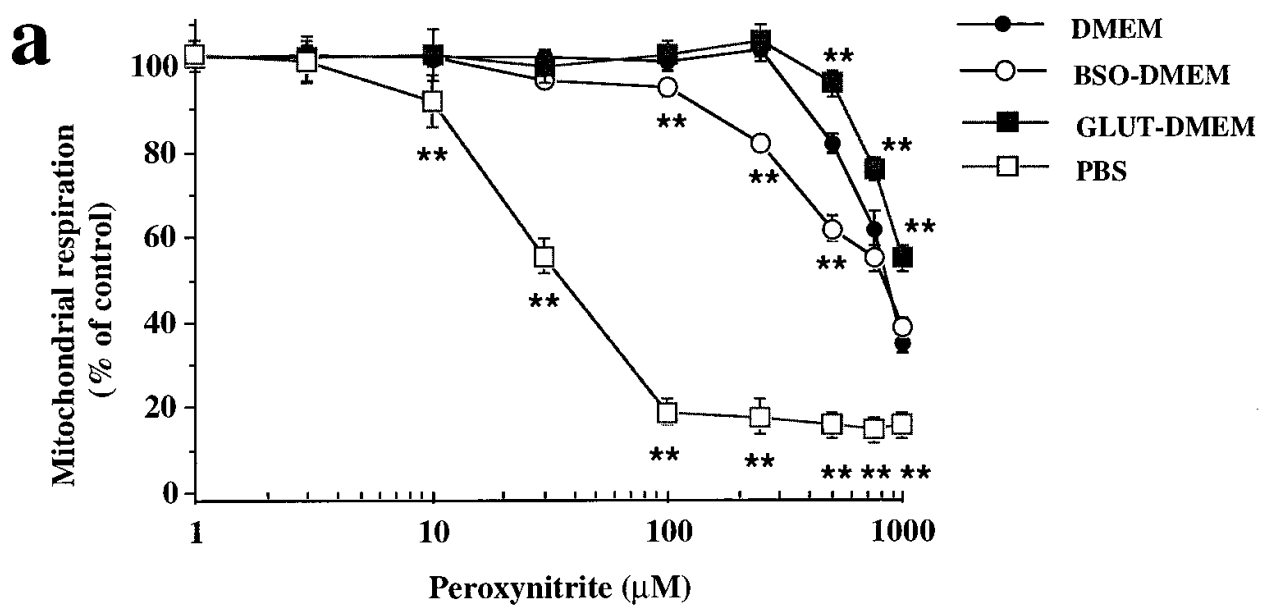

Figure 6. Cytotoxic and cytoprotective interactions of peroxynitrite in HUVEC. (a) Mitochondrial respiration at $1 \mathrm{~h}$ after exposure of HUVEC to increasing concentrations of peroxynitrite in regular medium; in regular medium after depletion of endogenous glutathione stores by treatment with buthionine sulfoximide (BSO-DMEM); in regular medium in the presence of 3 mM glutathione (GLUT-DMEM); and in PBS. $* * P<0.01$ represents significant difference at a given concentration when compared to control. (b) Interactions of peroxynitrite, hydrogen peroxide, and nitric oxide on the mitochondrial respiration in HUVEC. Depicted are the effects of hydrogen peroxide $\left(\mathrm{H}_{2} \mathrm{O}_{2}\right.$, $1 \mu \mathrm{M})$, peroxynitrite $\left(\mathrm{ONOO}^{-}\right.$, $250 \mu M)$, and their combination; and $(S N A P, 1 \mathrm{mM})$, peroxynitrite $\left(\mathrm{ONOO}^{-}, 1 \mathrm{mM}\right)$, and their combination. Respiration in control cells is considered as $100 \%(C)$. $* * P<$ 0.01 represents significant suppression of the mitochondrial respiration elicited by the various agents when compared to unstimulated controls; ${ }^{\# \#} P<0.01$ represents significant difference between various groups as indicated. Data are expressed as means \pm SEM of $n=$ 6-12 wells.

pound SNAP remained unaltered (Fig. 8). Inhibition of PARS activity by 3 -aminobenzamide $(1 \mathrm{mM})$ did not affect the relaxations in vehicle-treated rings but protected against the development of endothelial dysfunction in rings exposed to peroxynitrite (Fig. 8).

Effect of in vivo PARS inhibition on the changes in endothelial function in endotoxic shock. Recently, we have provided evidence for the formation of peroxynitrite (assessed by nitrotyrosine immunohistochemistry) in the various parts, including the intima, of thoracic aortic rings obtained from rats subjected to endotoxic shock $(6,26)$, and there is pharmacological evidence suggesting that the generation of peroxynitrite in the vicinity of the endothelium contributes to the development of endothelial dysfunction in this condition (see Discussion). In vascular rings obtained from rats injected with LPS, we found a significant reduction of the endothelium-dependent relaxations at $6 \mathrm{~h}$ after LPS (Fig. $9 a$ ). Treatment of the animals with 3 -aminobenzamide did not affect the relaxations in response to acetylcholine in control rings, but significantly improved the relaxations in rings obtained from LPS-treated animals (Fig. 9a).
In contrast to the marked impairment of the maximal relaxations elicited by acetylcholine in LPS-treated rats (Fig. 9a), the maximal relaxations to the NO donor compound SNAP did not change with endotoxemia (Fig. $9 \mathrm{~b}$ ), indicating the maintained ability of the smooth muscle relaxant machinery to respond to NO. There was, however, a slight but significant shift to the right in the SNAP dose-response curve in the LPStreated animals, which was unaffected by 3 -aminobenzamide treatment (Fig. $9 b$ ). The slight impairment of the vascular relaxations of NO donors after LPS treatment, which has recently been described by several groups in vascular rings from endotoxemic animals $(27,28)$, may be related to a slight impairment of the smooth muscle to relax in response to cyclic $\operatorname{GMP}(27,28)$.

The current protocol of in vivo inhibition of PARS by 3-aminobenzamide did not affect the expression of the inducible isoform of NOS (iNOS) in the animals, as confirmed by the measurement of circulating nitrite plus nitrate levels and by measurement of calcium-independent conversion of L-arginine to L-citrulline in lung samples (Fig. 10). 
$\mathbf{a}$

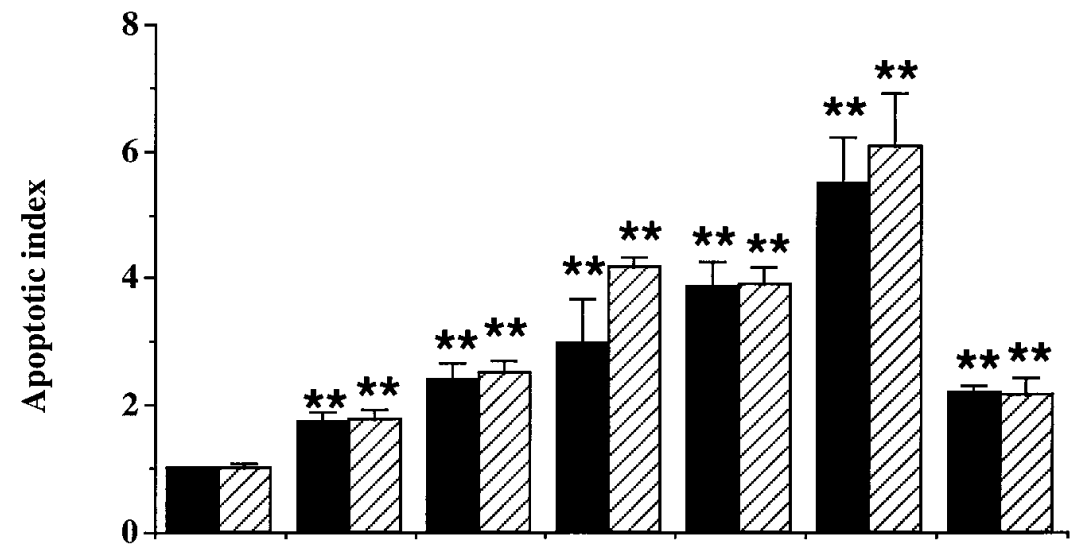

b

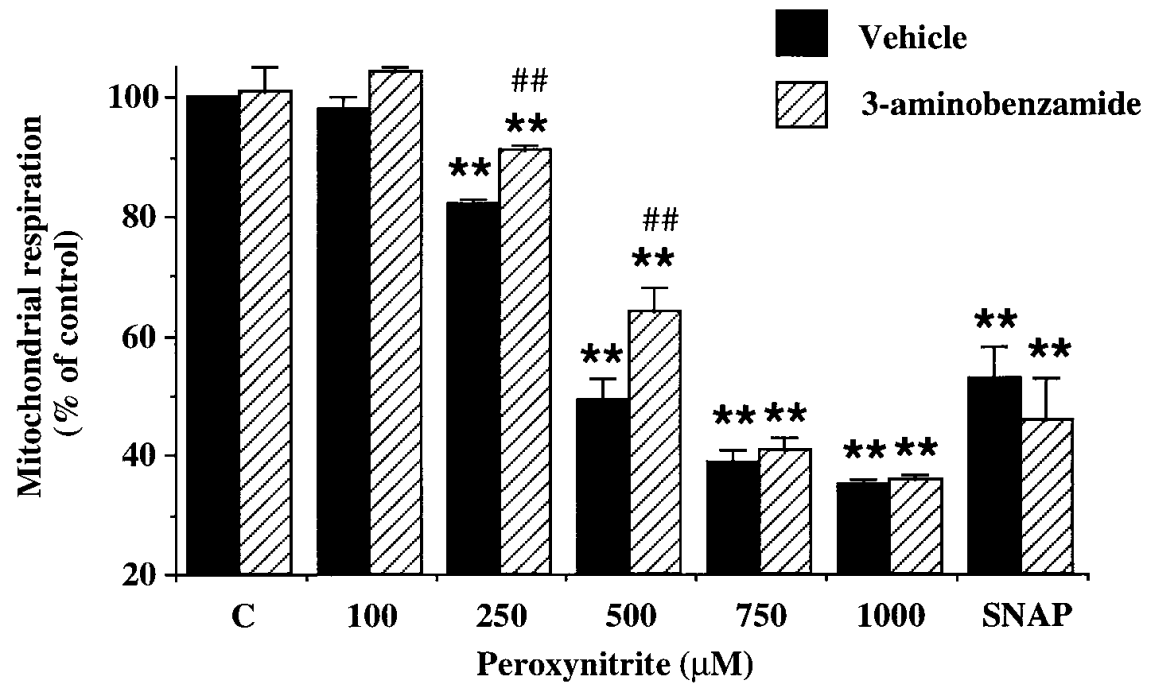

Figure 7. Apoptotic index $(a)$ and mitochondrial respiration $(b) 24 \mathrm{~h}$ after exposure of HUVEC with authentic peroxynitrite $(250 \mu \mathrm{M}$ to $1 \mathrm{mM})$ and SNAP (3 mM) in the absence (closed bars) and in the presence (hatched bars) of the PARS inhibitor 3-aminobenzamide (1 mM). Apoptotic index and respiration in control cells is considered as 1 and $100 \%$, respectively $(C)$. $* * P<0.01$ represents significant increase in the apoptotic index or suppression of the mitochondrial respiration elicited by peroxynitrite or SNAP; ${ }^{\#} P<0.01$ represents significant protection by 3 -aminobenzamide. Data are expressed as means \pm SEM of $n=6-12$ wells.

\section{Discussion}

Role of PARS in the peroxynitrite-induced acute endothelial cytotoxicity. PARS is a protein-modifying and nucleotide-polymerizing enzyme that is abundantly present in the nucleus of mammalian cells. The activation of PARS in response to DNA single strand breakage results in the cleavage of $\mathrm{NAD}^{+}$into ADP-ribose and nicotinamide. In turn, PARS covalently attaches ADP-ribose to various proteins, including nuclear proteins, histones, and an automodification domain of PARS itself. PARS then extends the initial ADP-ribose group into a nucleic acid-like polymer, poly (ADP) ribose. The resulting massive poly (ADP) ribosylation can suppress the metabolic activity of the cells, and may lead to cellular injury $(29,30)$. The physiological function of PARS has been the subject of debate over the last two decades. According to the latest evidence, PARS does not appear to be obligatory for DNA repair, but may play a role in the regulation of gene expression and cell differentiation $(18,30)$.

DNA single strand breakage is an obligatory trigger for the activation of PARS $(11,20,29)$. In endothelial cells, in response to hydrogen peroxide-induced oxidant damage and radiation injury, it has been proposed that pronounced activation of PARS can rapidly deplete the intracellular concentration of its substrate, $\mathrm{NAD}^{+}$, slowing the rate of glycolysis, electron transport, and, therefore, ATP formation, resulting in cell dysfunction and cell death (31-34). Accordingly, inhibitors of PARS protect against cell death under these conditions (3134). This mechanism, known as the PARS suicide hypothesis, has been subsequently proposed to occur in neurons and pancreatic islet cells in response to $\mathrm{NO}$ overproduction $(24,35$, 36). Additional studies, as well as theoretical considerations suggest, however, that the active species responsible for DNA injury and PARS activation in these studies was, in fact, peroxynitrite, rather than $\mathrm{NO}(11,37)$.

Our group (7-11) and others (38) have demonstrated that peroxynitrite (but not high concentrations of NO alone) potently triggers DNA single strand breakage in a number of cell types studied, including thymocytes, macrophages, and vascular smooth muscle cells. In addition, we have found that in J774 macrophages and rat aortic smooth muscle cells exposed to authentic peroxynitrite, the development of DNA strand breaks results in the activation of PARS with consequent reduction of intracellular $\mathrm{NAD}^{+}$, ATP, and mitochondrial respiration (7-11). The metabolic changes, but not the development of DNA strand breaks, can be ameliorated by pharmacological inhibition of PARS (7-11).

Peroxynitrite production has been suggested to contribute to endothelial injury in ischemia-reperfusion, shock, and atherosclerosis $(5,6,16)$. In fact, Villa et al. (39) have directly 



b

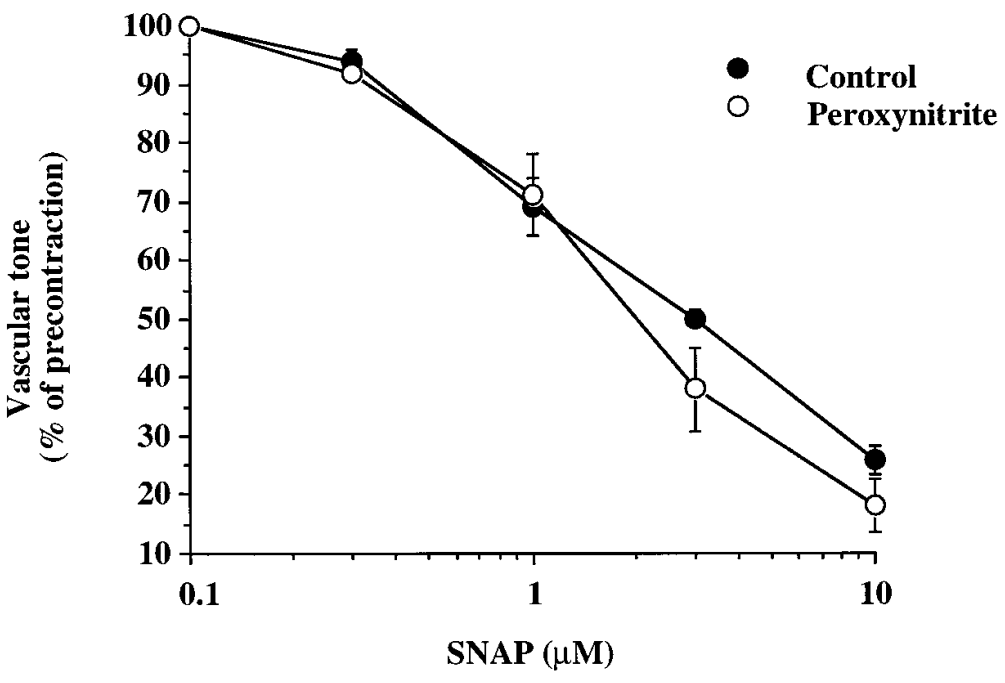

Figure 8. Endothelium-dependent relaxations to acetylcholine $(a)$ or to the NO donor SNAP $(b)$ in control rings and in rings exposed to peroxynitrite $(600 \mu \mathrm{M})$. The left panel of $a$ shows the lack of effect by the PARS inhibitor 3-aminobenzamide $(1 \mathrm{mM})$ on the endothelium-dependent relaxations to acetylcholine in control rings. The right panel of $a$ shows a significant impairment of the endothelium-dependent relaxations after peroxynitrite exposure $(* * P<0.01)$, and a significant prevention of this impairment by the PARS inhibitor 3-aminobenzamide (\#\# $P<0.01) . b$ demonstrates the lack of effect of peroxynitrite exposure on the relaxations elicited by SNAP. Data represent means \pm SEM of $n=6-8$ vascular rings.

demonstrated in isolated perfused hearts that infusion of authentic peroxynitrite into these hearts results in an impairment of the endothelium-dependent relaxations. In light of these previous studies, here we investigated whether peroxynitriteinduced endothelial cell cytotoxicity is associated with DNA single strand breakage, and whether the consequent activation of PARS contributes to the cytotoxicity. Our current data demonstrate that in HUVEC, peroxynitrite exposure results in DNA injury, PARS activation, and suppression of mitochondrial respiration. Furthermore, both the suppression of the mitochondrial respiration in HUVEC and the development of endothelial dysfunction in aortic rings can be ameliorated by 3-aminobenzamide, a pharmacological inhibitor of PARS, which neither inhibits DNA strand breakage, the trigger of PARS activation, nor is a scavenger of NO, superoxide, or peroxynitrite (8). A significant protection against peroxynitrite cytotoxicity was demonstrated with a range of inhibitors of different structural classes, and was also observed in a fibroblast line that lacks the functional PARS enzyme (Fig. 4).

Interestingly, the protection offered by pharmacological inhibitors of PARS or by the $\mathrm{PARS}^{-/-}$phenotype against the peroxynitrite induced cytotoxicity waned when cells were exposed to very high (millimolar) concentrations of peroxynitrite. Similarly, 3-aminobenzamide was no longer effective in inhibiting the development of endothelial dysfunction when vascular rings were treated with millimolar concentrations of peroxynitrite (unpublished observations). A likely explanation for these findings is that peroxynitrite triggers PARS-independent, parallel cytotoxic mechanisms. At lower concentrations of peroxynitrite, inhibition of PARS is sufficient to influence the net cellular energetic changes while at higher concentrations of peroxynitrite an overwhelming cytotoxicity occurs. PARS-independent cytotoxic mechanisms presumably include a direct inhibition of mitochondrial respiration, inhibition of membrane pumps, lipid peroxidation, and protein oxidation and nitration $(5,6)$. Similar to our current findings, a recent report by Kolb and co-workers (24) in primary islet cell cultures demonstrates that the lack of PARS gene protects against intermediate concentrations of oxidants, but no longer provides a protection against the cytotoxic effects of NO donors and oxidants when extremely high concentrations of these agents are used. In vivo, under inflammatory conditions, cells are likely to be exposed to lower concentrations of peroxynitrite for prolonged periods of time $(5,6)$. Therefore, the exposure of cells to lower concentrations of peroxynitrite is more likely to correspond to the in vivo situation.

Role of PARS in the peroxynitrite-induced delayed endothelial cytotoxicity (programmed cell death). Programmed cell death (apoptosis) is known to occur in various cell types as a delayed response to oxidant stress $(21,40,41)$. In a variety of pathophysiological conditions, such as acute inflammation, atherosclerosis, transplant rejection and allograft arteriopathy, 
a

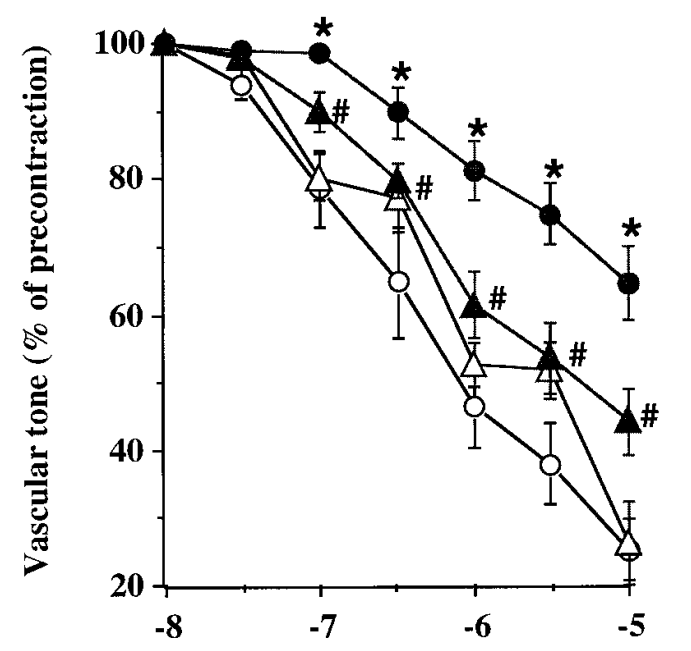

Acetylcholine ( $\log M)$

\section{b}

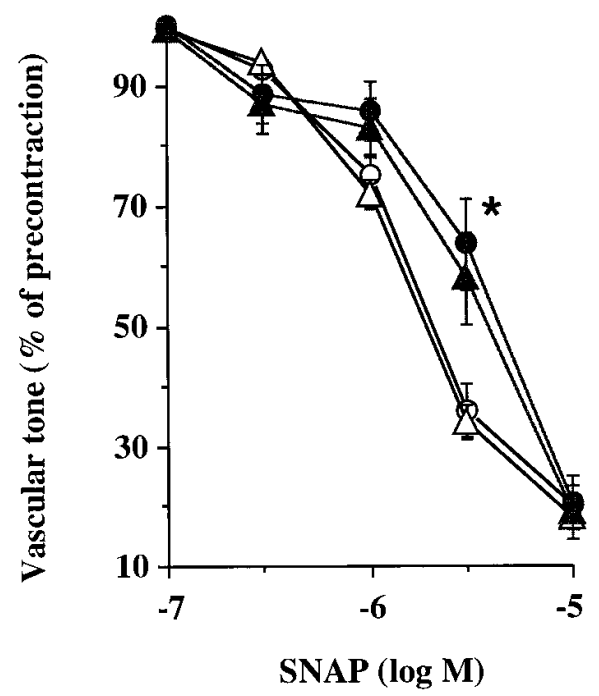

Figure 9. Endothelium-dependent relaxations to acetylcholine (a) and endothelium-independent relaxations to the NO donor SNAP (b) in thoracic aortic rings from control animals (C, open circles), in rings from control animals treated with the PARS inhibitor 3-aminobenzamide $(\mathrm{C}+3-\mathrm{AB}$, open triangles $)$, in rings from rats treated with LPS (LPS, closed circles) and in rings treated with LPS and 3-aminobenzamide (LPS +3 -AB, closed triangles). There was a significant impairment of the endothelium-dependent relaxations in endotoxemia $(* P<0.05)$ and a significant prevention of this impairment by the PARS inhibitor 3 -aminobenzamide $\left({ }^{\#} P<0.05\right)$. Data represent means \pm SEM of $n=6-8$ vascular rings.

recent reports have demonstrated the occurrence of apoptotic endothelial cell death (40-45). Current findings have established that peroxynitrite is able to cause apoptosis in various cell types (46-48). Our current data, demonstrating the delayed cytoplasmatic release of free histones (a marker of apoptotic cell death) (21) also demonstrated that peroxynitrite causes delayed apoptotic cell death in HUVEC in culture.

There are numerous conflicting reports describing the potential involvement of PARS in the process of apoptosis. $\mathbf{a}$
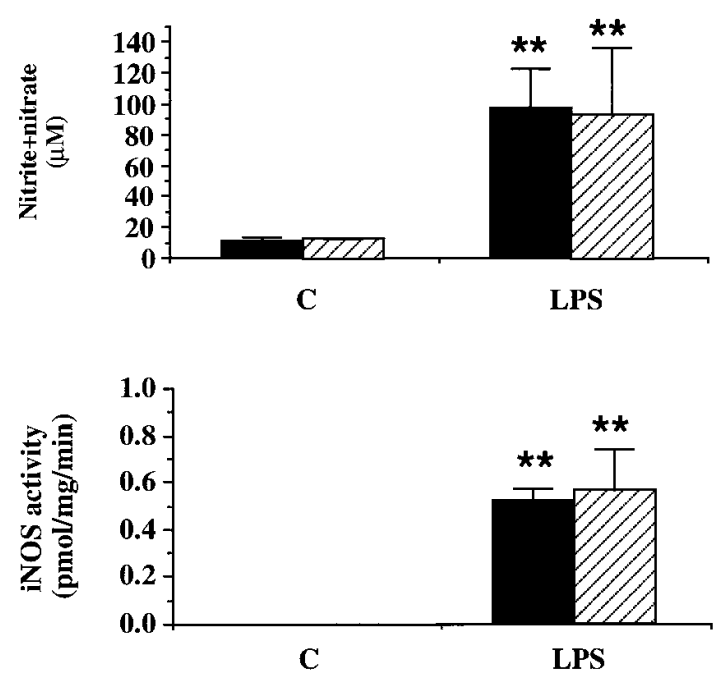

Figure 10. Plasma nitrite + nitrate concentrations ( $a$ ) and lung iNOS activity $(b)$ in rats at $6 \mathrm{~h}$ after LPS exposure in the presence or absence of 3-aminobenzamide treatment. $* * P<0.01$ represents significant increase in plasma nitrite + nitrate or lung iNOS activity in response to LPS. Treatment with 3-aminobenzamide did not affect the induction of iNOS or the production of nitrite + nitrate in response to LPS. Data are expressed as means \pm SEM of $n=4-7$ samples.

While in some experimental systems PARS inhibitors can prevent or delay apoptosis, in other studies, similar inhibitors are without effect, or even may induce apoptotic cell death (4951). It is conceivable that the effect of PARS inhibitors on the course of the apoptotic process is dependent on the apoptotic trigger, the cell type studied, and the metabolic status of the cells. In this study, we did not observe a protection against the apoptotic cell death by 3 -aminobenzamide. This finding is in line with a recent report showing the lack of effect of PARS inhibition on the apoptosis elicited by NO in murine macrophages (52). Taken together, our results suggest that while PARS inhibitors protect against the endothelial metabolic suppression in response to intermediate (but not extremely high) concentrations of peroxynitrite, they are not protective against the development of delayed apoptotic cell death in response to low concentrations of peroxynitrite. Although there is evidence that the apoptotic cell death can be a late consequence of cellular metabolic inhibition (53), our data do not support the view that, in this particular experimental system, improvement of the cellular metabolic status alone is sufficient to prevent or delay programmed cell death.

In this respect, our conclusions are similar to the ones reached by Watson et al. (54) in cultured intestinal epithelial cells exposed to hydrogen peroxide: inhibition of PARS prevented the early metabolic inhibition but failed to affect the course of the delayed apoptotic process.

Role of PARS in the development of endothelial dysfunction in endotoxic shock. The production of peroxynitrite in endotoxic shock has been demonstrated using several methods. Nitration of tyrosine is a specific process which is initiated by peroxynitrite, but does not occur in response to $\mathrm{NO}$ or oxyradicals $(5,6)$. Using nitrotyrosine immunohistochemistry, we have obtained evidence for the production of peroxynitrite in the tho- 
racic aorta of rats subjected to several hours of severe endotoxic shock (30). Similarly, in the lung and other tissues of rodents subjected to endotoxic shock, a marked nitrotyrosine staining has been reported (55). Using a different method, which uses the oxidation of dihydrorhodamine 123 to rhodamine in the plasma of animals subjected to various forms of shock, we also found evidence for peroxynitrite formation in endotoxic shock, hemorrhagic shock, and the reperfusion phase of splanchnic artery occlusion/reperfusion injury (56).

What is the evidence for a role of peroxynitrite in the pathogenesis of the endothelial dysfunction in endotoxic shock? We have observed recently that a manganese-mesoporphyrin cell-permeable superoxide dismutase analog and peroxynitrite scavenger (57) protects against the development of endothelial dysfunction in endotoxic shock (58). Similarly, selective inhibition of the inducible isoform of NO synthase by canavanine (59) or by the novel iNOS inhibitor guanidinoethyldisulfide (60) also provides protection against the endothelial dysfunction and the endothelial morphological damage in vessels obtained from rats subjected to endotoxin shock. One possible rationalization of the above mentioned results is that iNOS-derived NO combines with superoxide (the latter derived from activated neutrophils, and other sources) to form peroxynitrite, which, in turn, causes endothelial injury.

Our results confirmed previous observations showing impairment of the endothelium-dependent relaxations in endotoxemia (61-63). Moreover, our data, demonstrating protective effects of 3-aminobenzamide against the development of endothelial dysfunction in vascular rings obtained from rats with endotoxic shock, suggest that DNA strand breakage and PARS activation occur in endothelial cells during shock and that the subsequent energetic failure reduces the ability of the cells to generate NO in response to acetylcholine-induced activation of the muscarinic receptors on the endothelial membrane. Indeed, in vitro data exist that demonstrate DNA injury, PARS activation and consequent cytotoxicity in endothelial cells exposed to hydroxyl radical generators (31-34), or in response to peroxynitrite (current study). The relative contribution of peroxynitrite versus hydroxyl radical in the PARS activation and endothelial injury in shock remains to be further investigated. Both species are known to be produced in shock (1-6), and the available scavengers (such as superoxide dismutase analogs) would reduce the production of both peroxynitrite and hydroxyl radical. The data with iNOS inhibitors demonstrating protection against the endothelial injury in endotoxic shock $(59,60)$ would suggest the contribution of an NO-derived species, presumably peroxynitrite. Based on our in vitro data, demonstrating the synergistic cytotoxic interactions of hydrogen peroxide and peroxynitrite, it is conceivable that a similar synergism may also exist in vivo, and both peroxynitrite and hydroxyl radical contribute to the activation of PARS and the subsequent endothelial injury in vivo.

Conclusions: the role of PARS and peroxynitrite in shock and inflammation. Our data suggests that PARS activation plays a role in the pathogenesis of endothelial injury in endotoxic shock. Our recent studies have demonstrated that PARS activation is also involved in the vascular hypocontractility (9) and the cellular metabolic failure (8) associated with endotoxic shock. Moreover, current in vitro data show that peroxynitrite can cause hyperpermeability in epithelial cell monolayers, and this effect is ameliorated by pharmacological inhibition of PARS (10). The protection by PARS inhibition against multi- ple constituents of the inflammatory response is likely to explain how inhibitors of PARS improve survival rate in a murine model of lethal endotoxemia (9).

As discussed above, peroxynitrite and hydroxyl radical, possibly in concert, are likely to trigger DNA strand breakage and subsequent PARS activation. From in vitro studies, it appears that the key determinant of the oxidant potential of peroxynitrite is not the amount of NO or superoxide produced, but the ratio of the two precursors: excess NO inhibits oxidative processes triggered by peroxynitrite $(56,64,65)$. This latter phenomenon may well explain our finding that the NO donor SNAP reduces the peroxynitrite-induced suppression of mitochondrial respiration in HUVEC (Fig. $6 b$ ). Such interactions of NO with peroxynitrite may also explain our previous observation that in the delayed phase of endotoxic shock, when large amounts of NO are produced by iNOS, there was no marked additional increase in dihydrorhodamine oxidation (a marker of peroxynitrite formation), in comparison to earlier time points in the same shock model (14). The fact that excess NO reduces peroxynitrite-induced oxidations may result in paradoxical findings where both inhibitors of NOS and donors of NO may protect against peroxynitrite-induced oxidative injury. However, beneficial effects of NO donors against the development of endothelial dysfunction in shock involve many other mechanisms as well, such as regional vasodilatation, inhibition of platelet, and neutrophil adhesion and activation and effects on the expression of adhesion molecules (66-68).

Activation of PARS by hydroxyl radical, NO, and/or by peroxynitrite has been suggested to play a crucial role in the pathogenesis of neuronal injury during stroke and Parkinson's disease $(36,37,69)$, as well as in autoimmune pancreatic islet cell injury $(35,40,70,71)$. Our data demonstrates that inhibition of PARS is a novel strategy for improving endothelial function in circulatory shock. While, in principle, there are several approaches available to reduce NO or peroxynitrite-related cytotoxicity (NOS inhibitors, peroxynitrite scavengers, oxyradical scavengers, to name but a few), inhibition of PARS may be a viable strategy for several reasons: $(a)$ inhibition of PARS is not likely to interfere with the physiological roles of NO; $(b)$ inhibition of PARS affects multiple aspects of the inflammatory response in shock, such as endothelial and epithelial dysfunction, vascular hypocontractility, and cellular energetic failure (7-11 and this study); and (c) since invading prokaryotes do not contain PARS, pharmacological inhibition of PARS is unlikely to compromise NO- or peroxynitrite-mediated host defense systems. One has to keep in mind, however, that PARS activation represents only one, albeit important, pathway of the peroxynitrite-induced cytotoxicity. Thus, inhibitors of PARS cannot be expected to reduce all peroxynitrite-mediated oxidant injury (such as direct inhibition of mitochondrial respiration, lipid peroxidation, protein oxidation, and effects on signal transduction). The practical usefulness of PARS inhibitors, alone or in combination with other approaches, requires further investigations for the experimental therapy of inflammation and shock.

\section{Acknowledgments}

The assistance of Ms. V. Xie with the tissue cultures is appreciated.

This work was supported by a grant from the American Heart Association (Ohio Section) and by a grant from the National Institutes of Health (R29GM 54773) to Dr. C. Szabó. 


\section{References}

1. Youn, Y.K., C. LaLonde, and R. Demling. 1991. Use of antioxidant therapy in shock and trauma. Circ. Shock. 35:245-249.

2. McCord, J. 1993. Oxygen-derived free radicals. New Horizons. 1:70-76.

3. Szabó, C., and C. Thiemermann. 1994. Invited opinion: role of nitric oxide in haemorrhagic, traumatic and anaphylactic shock and in thermal injury. Shock. 2:145-155.

4. Szabó, C. 1995. Alterations in the production of nitric oxide in various forms of circulatory shock. New Horizons. 3:3-32

5. Crow, J.P., and J.S. Beckman. 1995. The role of peroxynitrite in nitric oxide-mediated toxicity. Curr. Top. Microbiol. Immunol. 196:57-73.

6. Szabó, C. 1996. The role of peroxynitrite in the pathophysiology of shock, inflammation and ischemia-reperfusion injury. Shock. 6:79-88.

7. Szabó, C., B. Zingarelli, M. O’Connor, and A.L. Salzman. 1996. DNA strand breakage, activation of poly-ADP ribosyl synthetase, and cellular energy depletion are involved in the cytotoxicity in macrophages and smooth muscle cells exposed to peroxynitrite. Proc. Natl. Acad. Sci. USA. 93:1753-1758.

8. Zingarelli, B., M. O'Connor, H. Wong, A.L. Salzman, and C. Szabó. 1996. Peroxynitrite-mediated DNA strand breakage activates poly-ADP ribosyl synthetase and causes cellular energy depletion in macrophages stimulated with bacterial lipopolysaccharide. J. Immunol. 156:350-358.

9. Szabó, C., B. Zingarelli, and A.L. Salzman. 1996. Role of poly-ADP ribosyltransferase activation in the nitric oxide- and peroxynitrite-induced vascular failure. Circ. Res. 78:1051-1063.

10. Szabó, C., C. Saunders, M. O'Connor, and A.L. Salzman. 1996. Peroxynitrite causes energy depletion and increases permeability via activation of poly-ADP ribosyl synthetase in pulmonary epithelial cells. Am. J. Respir. Cell. Mol. Biol. 16:105-109.

11. Szabó, C. 1996. DNA strand breakage and activation of poly-ADP ribosyltransferase: a cytotoxic pathway triggered by peroxynitrite. Free Radical Biol. Med. 21:855-869.

12. Darley-Usmar, V., H. Wiseman, and B. Halliwell. 1995. Nitric oxide and oxygen radicals: a question of balance. FEBS Lett. 369:131-135.

13. Darley-Usmar, V., and B. Halliwell. 1996. Blood radicals. Reactive nitrogen species, reactive oxygen species, transition metal ions, and the vascular system. Pharmacol. Res. 13:649-662.

14. Katusic, Z. 1996. Superoxide anion and endothelial regulation of arterial tone. Free Radical Biol. Med. 20:443-448.

15. White, C.R., T.A. Brock, L.Y. Chang, J. Crapo, P. Briscoe, D. Ku, W.A. Bradley, S.H. Gianturco, J. Gore, et al. 1994. Superoxide and peroxynitrite in atherosclerosis. Proc. Natl. Acad. Sci. USA. 9:1044-1048.

16. Xia, Y., V.L. Dawson, T.M. Dawson, S.H. Snyder, and J.L. Zweier. 1996. Nitric oxide synthase generates superoxide and nitric oxide in argininedepleted cells leading to peroxynitrite-mediated cellular injury. Proc. Natl. Acad. Sci. USA. 93:6770-6774.

17. Hoshi, H., and W.L. McKeehan. 1984. Brain and liver cell-derived factors are required for growth of human endothelial cells in serum-free culture. Proc. Natl. Acad. Sci. USA. 81:6413-6417.

18. Wang, Z.Q., B. Auer, L. Stingl, H. Berghammer, D. Haidacher, M. Schweiger, and E.F. Wagner. 1995. Mice lacking ADPRT and poly(ADP-ribosyl)ation develop normally but are susceptible to skin disease. Genes Dev. 9:510-520.

19. Banasik, M., H. Komura, M. Shimoyama, and K. Ueda. 1992. Specific inhibitors of poly (ADP-ribose) syntethase and mono (ADP-ribosyl) transferase. J. Biol. Chem. 267:1569-1575.

20. Andreoli, S.P., C.P. Mallett, and J.M. Bergstein. 1986. Role of glutathione in protecting endothelial cells against hydrogen peroxide oxidant injury. J. Lab. Clin. Med. 108:190-198.

21. Bingisser, R., C. Stey, M. Weller, P. Groscurth, E. Russi, and K. Frei. 1996. Apoptosis in human alveolar macrophages is induced by endotoxin and is modulated by cytokines. Am. J. Respir. Cell. Mol. Biol. 15:64-70.

22. Szabó, C., C. Thiemermann, C.C. Wu, M. Perretti, and J.R. Vane. 1994. Inhibition of nitric oxide synthase induction by endogenous glucocorticoids accounts for endotoxin tolerance in vivo. Proc. Natl. Acad. Sci. USA. 91:271-275.

23. Bauer, P.I., E. Kirsten, L.J.T. Young, G. Varadi, E. Csonka, K.G. Buki, G. Mikala, R. Hu, J.A. Comstock, J. Mendeleyev, et al. 1996. Modification of growth related enzymatic pathways and apparent loss of tumorigenicity of a ras-transformed bovine endothelial cell line by treatment with 5-iodo-6-amino1,2-benzopyrone. Int. J. Oncol. 8:239-252.

24. Heller, B., Z.Q. Wang, E.F. Wagner, J. Radons, A. Burkle, K. Fehsel, V. Burkart, and H. Kolb. 1995. Inactivation of the poly(ADP-ribose) polymerase gene affects oxygen radical and nitric oxide toxicity in islet cells. J. Biol. Chem. 270:11176-11180.

25. Reden, J. 1990. Molsidomine. Blood Vessels. 27:282-294.

26. Szabó, C., A.L. Salzman, and H. Ischiropoulos. 1995. Endotoxin triggers the expression of an inducible isoform of NO synthase and the formation of peroxynitrite in the rat aorta in vivo. FEBS Lett. 363:235-238.

27. Schneider, F., B. Bucher, C. Schott, A. Andre, G. Julou-Schaeffer, and J.C. Stoclet. 1994. Effect of bacterial lipopolysaccharide on function of rat small femoral arteries. Am. J. Physiol. 266:H191-H198.

28. Fullerton, D.A., R.C. McIntyre, A.R. Hahn, J. Agrafojo, K. Koike, X. Meng, A. Banerjee, and A.H. Harken. 1995. Dysfunction of cGMP-mediated pulmonary vasorelaxation in endotoxin-induced acute lung injury. Am. J. Physiol. 268:L1029-L1035.

29. Cochrane, C.G. 1991. Mechanism of oxidant injury of cells. Mol. Aspects Med. 12:137-147.

30. de Murcia, G., J. Menissier-de Murcia, and J. Schreiber. 1991. Poly(ADP-ribose) polymerase: molecular biological aspects. Bioessays. 13: 455-462.

31. Kirkland, J.B. 1991. Lipid peroxidation, protein thiol oxidation and DNA damage in hydrogen peroxide-induced injury to endothelial cells: role of activation of poly(ADP-ribose)polymerase. Biochim. Biophys. Acta. 1092:319-325.

32. Junod, A.F., L. Jornot, and H. Petersen. 1989. Differential effects of hyperoxia and hydrogen peroxide on DNA damage, polyadenosine diphosphateribose polymerase activity, and nicotinamide adenine dinucleotide and adenosine triphosphate contents in cultured endothelial cells and fibroblasts. J. Cell. Physiol. 140:177-185.

33. Thies, R.L., and A.P. Autor. 1991. Reactive oxygen injury to cultured pulmonary artery endothelial cells: mediation by polyADP-ribose polymerase activation causing NAD depletion and altered energy balance. Arch. Biochem. Biophys. 286:353-363.

34. Andreoli, S.P. 1989. Mechanisms of endothelial cell ATP depletion after oxidant injury. Pediatr. Res. 25:97-101.

35. Radons, J., B. Heller, A. Burkle, B. Hartmann, and M.L. Rodriguez. 1994. NO toxicity in islet cells involves polyADP-ribose-polymerase activation and concomitant NAD ${ }^{+}$depletion. Biochem. Biophys. Res. Comm. 199:12701277

36. Zhang, J., V.L. Dawson, T.M. Dawson, and S.H. Snyder. 1994. Nitric oxide activation of poly (ADP-ribose) synthetase in neurotoxicity. Science (Wash. DC). 263:687-689.

37. Snyder, S. 1996. No NO prevents parkinsonism. Nat. Med. 2:965-966.

38. Salgo, M.G., E. Bermudez, G. Squadrito, and W. Pryor. 1995. DNA damage and oxidation of thiols peroxynitrite causes in rat thymocytes. Arch. Biochem. Biophys. 322:500-505.

39. Villa, L.M., E. Salas, M. Darley-Usmar, M.E.W. Radomski, and S. Moncada. 1994. Peroxynitrite induces both vasodilatation and impaired vascular relaxation in the isolated perfused rat heart. Proc. Natl. Acad. Sci. USA. 91: 12383-12387.

40. Payne, C.M., C. Bernstein, and H. Bernstein. 1995. Apoptosis overview emphasizing the role of oxidative stress, DNA damage and signal-transduction pathways. Leuk. Lymphoma. 19:43-93.

41. Varani, J., and P.A. Ward. 1994. Mechanisms of endothelial cell injury in acute inflammation. Shock. 2:311-319.

42. Laurence, J., D. Mitra, M. Steiner, L. Staiano-Coico, and E. Jaffe. 1996. Plasma from patients with idiopathic and human immunodeficiency virus-associated thrombotic thrombocytopenic purpura induces apoptosis in microvascular endothelial cells. Blood. 87:3245-3254.

43. Young, D.S., M. Kadokura, I. Brockhausen, V. Kashef, and J.G. Coles. 1996. Human serum-induced porcine endothelial cell apoptosis-another pathway to xenograft rejection. Transplant. Proc. 28:611-612.

44. Lizard, G., V. Deckert, L. Dubrez, M. Moisant, P. Gambert, and L. Lagrost. 1996. Induction of apoptosis in endothelial cells treated with cholesterol oxides. Am. J. Pathol. 148:1625-1638.

45. Dong, C., J.E. Wilson, G.L. Winters, and B.M. McManus. 1996. Human transplant coronary artery disease: pathological evidence for Fas-mediated apoptotic cytotoxicity in allograft arteriopathy. Lab. Invest. 74:921-931.

46. Bonfoco, E., D. Krainc, M. Ankarcrona, P. Nicotera, and S. Lipton. 1995. Apoptosis and necrosis: two distinct events induced, respectively, by mild and intense insults with NMDA or nitric oxide/superoxide in cortical cell cultures. Proc. Natl. Acad. Sci. USA. 92:7162-7166.

47. Lin, K.T., J.Y. Xue, M. Nomen, B. Spur, and P.Y. Wong. 1995. Peroxynitrite-induced apoptosis in HL-60 cells. J. Biol. Chem. 270:16487-16490.

48. Estevez, A.G., R. Radi, L. Barbeito, J.T. Shin, J.A. Thompson, and J.S Beckman. 1995. Peroxynitrite-induced cytotoxicity in PC12 cells: evidence for an apoptotic mechanism differentially modulated by neurotrophic factors. $J$. Neurochem. 65:1543-1550.

49. Monti, D., L. Troiano, F. Tropea, E. Grassilli, A. Cossarizza, D. Barozzi, M.C. Pelloni, M.G. Tamassia, G. Bellomo, and C. Francheschi. 1995. Apoptosis-programmed cell death: a role in the aging process? Am. J. Clin. Nutr. 55: 1208S-1214S

50. Nicholson, D.W., A. All, N.A. Thornberry, J.P. Vaillancourt, C.K. Ding, M. Gallant, Y. Gareau, P.R. Griffin, M. Labelle, Y.A. Lazebnik, et al. 1995. Identification and inhibition of the ICE/CED-3 protease necessary for mammalian apoptosis. Nature (Lond.). 376:37-43.

51. Rice, W.G., C.D. Hillyer, B. Harten, C.A. Schaeffer, M. Dorminy, D.A. Lackey, E. Kirsten, J. Mendeleyev, K. Buki, A. Hakam, et al. 1992. Induction of endonuclease-mediated apoptosis in tumor cells by C-nitroso-substituted ligands of poly(ADP-ribose) polymerase. Proc. Natl. Acad. Sci. USA. 89:77037707.

52. Messmer, U.K., and B. Brüne. 1996. Nitric oxide in apoptotic versus necrotic RAW 264.7 macrophage cell death: the role of NO donor exposure $\mathrm{NAD}^{+}$content and p53 accumulation. Arch. Biochem. Biophys. 327:1-10.

53. Richter, C., M. Schweizer, A. Cossariza, and C. Francheschi. 1996. Control of apoptosis by the cellular ATP level. FEBS Lett. 378:107-110. 
54. Watson, A.J., J.N. Askew, and R.S. Benson. 1996. Poly(adenosine diphosphate ribose) polymerase inhibition prevents necrosis induced by $\mathrm{H}_{2} \mathrm{O}_{2}$ but not apoptosis. Gastroenterology. 109: 472-482.

55. Wizemann, T., C. Gardner, J. Laskin, S. Quinones, S. Durham, N. Goller, T. Ohnishi, and D. Laskin. 1994. Production of nitric oxide and peroxynitrite in the lung during acute endotoxemia. J. Leukocyte Biol. 56:759-768.

56. Szabó, C., A.L. Salzman, and H. Ischiropoulos. 1995. Peroxynitrite-mediated oxidation of dihydrorhodamine 123 occurs in early stages of endotoxic and hemorrhagic shock and ischemia-reperfusion injury. FEBS Lett. 372:229-232.

57. Szabó, C., B.J. Day, and A.L. Salzman. 1996. Evaluation of the relative contribution of nitric oxide and peroxynitrite to the suppression of mitochondrial respiration in immunostimulated macrophages, using a novel mesoporphyrin superoxide dismutase analog and peroxynitrite scavenger. FEBS Lett. 381:82-86.

58. Zingarelli, B., B.J. Day, J. Crapo, A.L. Salzman, and C. Szabó. 1996. The potential involvement of peroxynitrite in the pathogenesis of endotoxic shock. Br. J. Pharmacol. 120:357-366.

59. Fatehi-Hassanabad, Z, H. Burns, E.A. Aughey, A. Paul, R. Plevin, J.R. Parratt, and B.L. Furman. 1996. Effects of L-canavenine, an inhibitor of inducible nitric oxide synthase on endotoxin mediated shock in rats. Shock. 6:194-200.

60. Szabó, C., R. Bryk, B. Zingarelli, G.J. Southan, T.C. Gahman, V. Bhat, A.L. Salzman, and D.J. Wolff. 1996. Pharmacological characterization of guanidinoethyldisulphide (GED), a novel inhibitor of nitric oxide synthase with selectivity towards the inducible isoform. Br. J. Pharmacol. 118:1659-1668.

61. Umans, J.G., M.E. Wylam, R.W. Samsel, J. Edwards, and P.T. Schumacker. 1993. Effects of endotoxin in vivo on endothelial and smooth-muscle function in rabbit and rat aorta. Am. Rev. Respir. Dis. 148:1638-1645.
62. Parker, J.L., and H.R. Adams. 1993. Selective inhibition of endothelium-dependent vasodilator capacity by escherichia-coli endotoxaemia. Circ. Res. 72:539-551.

63. Myers, P.R., Q. Zhong, J.J. Jones, M.A. Tanner, H.R. Adams, and J.L. Parker. 1995. Release of EDRF and NO in ex vivo perfused aorta: inhibition by in vivo E. coli endotoxemia. Am. J. Physiol. 268:H955-H961.

64. Rubbo, H., R. Radi, M. Trujillo, R. Telleri, B. Kalyanaraman, S. Barnes, M. Kirk, and B.A. Freeman. 1994. Nitric oxide regulation of superoxide and peroxynitrite-dependent lipid peroxidation. Formation of novel nitrogen-containing oxidized lipid derivatives. J. Biol. Chem. 269:26066-26075.

65. Miles, A.M., D.S. Bohle, P.A. Glassbrenner, B. Hansert, D.A. Wink, and M.B. Grisham. 1996. Modulation of superoxide-dependent oxidation and hydroxylation reactions by nitric oxide. J. Biol. Chem. 271:40-47.

66. Kanwar, S., and P. Kubes. 1995. Nitric oxide is an antiadhesive molecule for leukocytes. New Horizons. 3:93-104.

67. Vane, J.R., and R.M. Botting. 1994. Mediators from the endothelial cell and their participation in inflammation. Int. J. Tissue React. 16:19-49.

68. Lefer, A.M. 1995. Attenuation of myocardial ischemia-reperfusion injury with nitric oxide replacement therapy. Ann. Thorac. Surg. 60:847-851.

69. Szabó, C. 1996. Role of nitric oxide in the central nervous system. Brain Res. Bull. 41:131-141.

70. Masiello, P., T.L. Cubeddu, G. Frosina, and E. Bergamini. 1985. Protective effect of 3-aminobenzamide, an inhibitor of poly (ADP-ribose) synthetase, against streptozotocin-induced diabetes. Diabetologia. 28:683-686.

71. Okamoto, H. 1981. Regulation of proinsulin synthesis in pancreatic islets and a new aspect to insulin-dependent diabetes. Mol. Cell. Biochem. 37:43-61. 